\title{
Interaction of Natural Dye (Allium cepa) with Ionic Surfactants
}

\author{
Shalini Chandravanshi and Santosh K. Upadhyay \\ Department of Chemistry, Harcourt Butler Technological Institute, Nawabganj, Kanpur 208002, India \\ Correspondence should be addressed to Santosh K. Upadhyay; upadhyay_s_k@rediffmail.com
}

Received 23 June 2012; Accepted 15 August 2012

Academic Editor: Joël Fleurence

Copyright (C) 2013 S. Chandravanshi and S. K. Upadhyay. This is an open access article distributed under the Creative Commons Attribution License, which permits unrestricted use, distribution, and reproduction in any medium, provided the original work is properly cited.

\begin{abstract}
Allium cepa is a natural dye that has been extracted from onion skin with the help of soxhlet apparatus. The pigment in the dye pelargonidin was found to be $2.25 \%$. The interaction of the dye with ionic surfactants, namely, cationic surfactant (cetyltrimethylammonium bromide) and anionic (sodium lauryl sulphate) has been studied by spectrophotometrically, conductivity, and surface tension measurements. The thermodynamic and surface parameters have been evaluated for the interaction process. The results indicate \{surfactant-dye complex formation and domination of adsorption in comparison to micellization.
\end{abstract}

\section{Introduction}

Synthetic dyes almost have their origin from coal tar that leads to the formation of harmful atmospheric gases [1]. Several synthetic colorants have been banned because they cause allergic effects. Natural dyes are derived from naturally occurring sources such as plants, insects, animals, and minerals. Natural dyes are generally ecofriendly and can provide a wide range of beautiful shades with acceptable levels of color fastness [2-5]. A number of commercial dyes and textiles mills/plants started looking at the possibilities of using natural dyes to overcome environmental pollution caused by synthetic dyes. Various reports [6-8] have been appeared on the behavior and applications of the natural dyes on textiles.

Surfactants containing both hydrophilic and hydrophobic moieties are extensively used in our daily life and also in various industrial processes such as textiles, pulp, and paper industry. The use of water as a medium for textile processing ideally requires liquid that wets the fiber surface quickly and uniformly and here surfactants play a useful role because these can be used as leveling, dispersing, and wetting agents. Surfactants are required for level dyeing and so on [9-15]. The surfactants act mostly in two ways, either they can form a complex with ionic dyes or they can be adsorbed into the fiber. Surfactant-dye associations are important in various dyeing process such as textiles dyeing, photography, and in pharmaceuticals processes.

The studies on the interaction between natural dyes and surfactants are important and interesting for improving the dyeing process from theoretical, technological, ecological, and economical points of view. However, not much attention has been made on the interaction between natural dyes and surfactants. Recently, the interaction between some natural dyes (Rubia cordifolia and Punica granatum) with anionic and cationic surfactants has been made and the results were found to be encouraging [16]. Therefore, it was worthwhile to make further studies involving some more natural dyes.

In the present communication the results of interaction of allium cepa dye with cationic surfactant (cetyltrimethylammonium bromide) and anionic surfactant (sodium lauryl sulphate) are reported.

1.1. Experimental. The extraction of dye pigment was followed as described by Önal [17]. Onion skin dye (allium серa) was extracted by soxhlet apparatus. Surfactants such as sodium lauryl sulphate and cetyltrimethylammonium bromide (Thomas baker, Mumbai, India) were used as such. However, the critical micelle concentration (CMC) of both the surfactants was determined by conductivity as well as surface tension measurement and was found to be $9.6 \times 10^{-4}$ 
TABLE 1: Spectroscopic data for the interaction of dyes with surfactants at $25^{\circ} \mathrm{C}$.

\begin{tabular}{lccc}
\hline Surfactant & $\begin{array}{c}\text { Surfactant } \\
\text { added } \\
(\mathrm{g} / \mathrm{L})\end{array}$ & $\begin{array}{c}\lambda_{\max } \text { and absorbance of dye }(1.0 \mathrm{~g} / \mathrm{L}) \\
\lambda_{\max \pm 2}\end{array}$ & $\begin{array}{c}\text { (Absorbance) } \\
(\mathrm{nm})\end{array}$ \\
\hline \multirow{4}{*}{ NaLS } & Nil & 535 & .36 \\
& 0.05 & 540 & .41 \\
& 0.10 & 540 & .44 \\
& 0.15 & 540 & .46 \\
\hline \multirow{3}{*}{ CTAB } & 0.05 & 545 & .42 \\
& 0.10 & 545 & .45 \\
& 0.15 & 545 & .48 \\
\hline
\end{tabular}

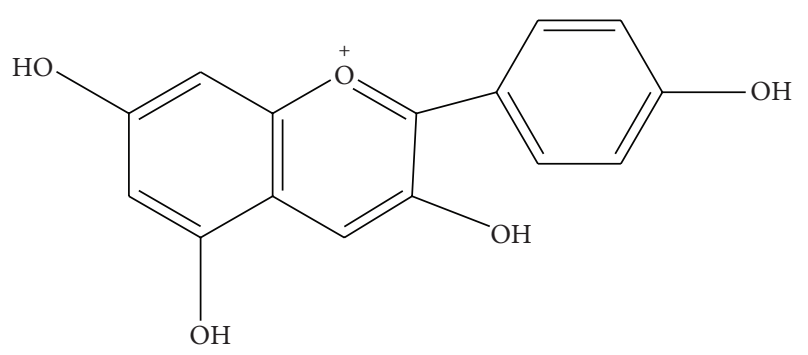

SCHEMe 1

and $8.1 \times 10^{-3} \mathrm{~mol} \mathrm{dm}^{-3}$ in case of CTAB [18] and NaLS [19], respectively. All the solutions used in the experiment are prepared using double-distilled water from alkaline $\mathrm{KMnO}_{4}$.

1.2. Extraction Method. Onion skin of known weight was minced. Then the minced onion skin was wrapped properly in extramicropore filter paper for $24 \mathrm{hr}$ for the removal of moisture if present. Soxhlet apparatus was used to extract the dyestuff from the onion skin. Absolute methanol of about $250 \mathrm{ml}$ was added to the minced onion skin then transferred into Soxhlet apparatus for 2-3 hr. Thereafter, the solvent was evaporated using rotatory evaporator for half an hour, and then dried dye was obtained and weighed. The amount of pelargonidin (pigment in dye of dark red color) was found to be $2.25 \%$.

1.3. Coloring Pigment in Dye. The skin of the onion is inedible (Allium cepa) and it contains a dyestuff called pelargonidin $(3,5,7,4$ tetrahydroxy anthocyanidin) (Scheme 1$)$.

Pelargonidin has four hydroxyl groups all of which are auxochrome groups such as $\mathrm{NH}_{2}, \mathrm{COOH}$. Consequently, pelargonidin exhibits good dyeing properties for the dyeing of wool, and so forth. As such, these four auxochrome groups form the stable complex compound which is best for wool dyeing.

1.4. Spectrophotometric Studies. The spectroscopic measurements were carried out on a visible spectrophotometer (TVSP-25, Toshniwal, India) and UV double-beam spectrophotometer 2203 (Systronics, India).
1.5. Conductivity Measurement. The specific conductivity ( $k$ ) of a series of solutions of surfactant and mixture of surfactant with dye at constant temperature $\left(25 \pm 0.1^{\circ} \mathrm{C}\right)$ were measured on an automatic conductivity meter (Systronic, India) with a conductivity cell-type CD-10 with platinum electrode embedded in glass and having cell constant of $1.0 \mathrm{~cm}^{-1}$. The (Specific Conductivity) versus [Surfactant] plot showed two straight lines with different slopes. The CMC of surfactant was determined from the point of intersection of these two straight lines.

1.6. Surface Tension Measurement. The surface tension of aqueous solutions of individual surfactant and dye-mixed surfactant were measured at $25^{\circ} \mathrm{C}$ using the Wilhelmy plate method on a tentiometer (DCAT ${ }_{21}$ Date Physics, Germany). The observed surface tension $(\gamma)$ of a solution was plotted against log [Surfactant]. The plot showed two straight lines with different slopes. The CMC of the solution was determined from the point of intersection of two straight lines.

\section{Results and Discussion}

2.1. Electronic UV-Visible Spectra. The absorbance of the extracted samples was measured at the wavelength ranging 200-700 $\mathrm{nm}$. The spectrum of onion skin dye (Allium cepa) in absence and in presence of surfactants, that is, cationic surfactant (cetyltrimethyl ammonium bromide) and anionic surfactant (sodium lauryl sulphate) has been observed. The results are shown in Figure 1. The average values of $\lambda_{\max }$ and absorbance at $\lambda_{\max }$ taken from three repeated experiments are given in Table 1 .

It can be seen that on addition of NaLS the $\lambda_{\max }$ shifted from $535 \mathrm{~nm}$ to $540 \mathrm{~nm}$, that is, towards longer wavelength while addition of CTAB results in a shift of $\lambda_{\max }$ from $535 \mathrm{~nm}$ to $545 \mathrm{~nm}$. An increase in absorbance intensity was also observed on increasing the amount of surfactants in dye solution (Table 1). The results clearly indicate an association/complexation between dye and surfactants. As the molecular weights of the natural dye could not be calculated due to various constituents present in dye, the detail study of the complex formed due to interaction of dye and surfactant could not be investigated.

2.2. Thermodynamic Parameters by Conductivity Method. In order to consider the effect of dye on the CMC of the surfactants, the specific conductivity of a series of solution in absence and in presence of different amount of dye in solution mixture has been measured. The results are given in the form of the plot of (Specific Conductivity) versus [Surfactant] in Figures 2 and 3 in case of NaLS and CTAB, respectively. The values of CMC of NaLS and CTAB in absence and in presence of different added amount of dye are given in Table 2. It is observed that on increasing amount of dye in aqueous surfactant solution, the CMC of the surfactant decreases. The degree of counter ion dissociation $(\beta)$ was obtained by the ratio of the slope of the postmicellar region $\left(\mathrm{S}_{2}\right)$ to that of premicellar region $\left(S_{1}\right)$. The observed regular increase in degree of counter ion dissociation on dye addition (Table 2) 
TABLE 2: Thermodynamic parameters for the interaction of dyes with surfactants at $25^{\circ} \mathrm{C}$ by conductivity method.

\begin{tabular}{|c|c|c|c|c|c|c|}
\hline Surfactant & $\begin{array}{l}{[\text { Dye] }} \\
\text { added } \\
(\mathrm{g} / \mathrm{L})\end{array}$ & $\begin{array}{c}\mathrm{CMC} \\
\left(\mathrm{mol} \mathrm{dm}^{-3}\right)\end{array}$ & $\begin{array}{c}\text { “ } \beta " \\
\text { Degree of counter } \\
\text { ion dissociation }\end{array}$ & $\begin{array}{c}-\Delta G_{\text {mic }}^{\circ} \pm 0.05 \\
\left(\mathrm{~kJ} \mathrm{~mol}^{-1}\right)\end{array}$ & $\begin{array}{l}\Delta S_{\text {mic }}^{\circ} \pm 0.10 \\
\left(\mathrm{JK}^{-1} \mathrm{~mol}^{-1}\right)\end{array}$ & $\begin{array}{c}\Delta H_{\text {mic }}^{\circ} \pm 0.05 \\
\left(\mathrm{~kJ} \mathrm{~mol}^{-1}\right)\end{array}$ \\
\hline \multirow{4}{*}{$\begin{array}{l}\text { CTAB } \\
(0.02 \mathrm{~g} / \mathrm{L})\end{array}$} & Nil & $9.8 \times 10^{-4}$ & 0.75 & 27.5 & 90.76 & -2.22 \\
\hline & 0.1 & $9.3 \times 10^{-4}$ & 0.87 & 27.22 & 91.33 & -0.56 \\
\hline & 0.2 & $8.8 \times 10^{-4}$ & 0.90 & 27.33 & 91.71 & -1.44 \\
\hline & 0.3 & $7.7 \times 10^{-4}$ & 0.91 & 27.67 & 92.86 & -1.09 \\
\hline \multirow{4}{*}{$\begin{array}{l}\mathrm{NaLS} \\
(0.20 \mathrm{~g} / \mathrm{L})\end{array}$} & Nil & $8.3 \times 10^{-3}$ & 0.66 & 21.79 & 73.14 & -0.62 \\
\hline & 0.1 & $7.7 \times 10^{-3}$ & 0.70 & 21.97 & 73.72 & +1.03 \\
\hline & 0.2 & $6.8 \times 10^{-3}$ & 0.80 & 22.25 & 74.67 & -1.15 \\
\hline & 0.3 & $6.3 \times 10^{-3}$ & 0.90 & 22.48 & 75.44 & -0.07 \\
\hline
\end{tabular}

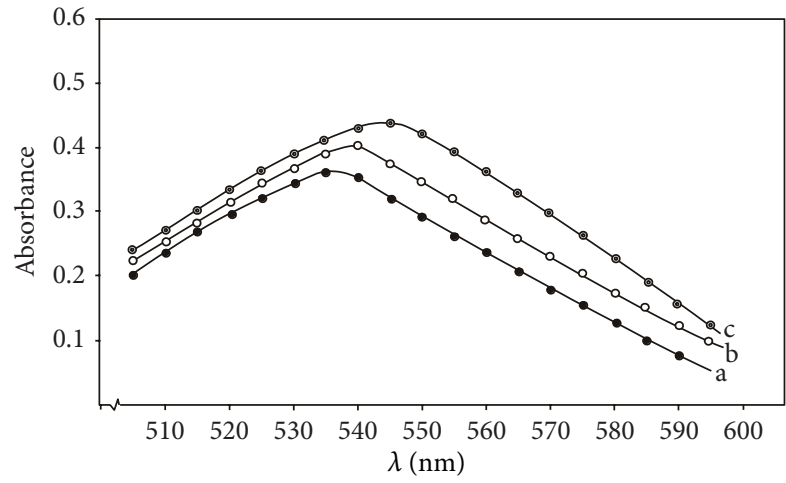

Figure 1: Plots of (Absorbance) versus wavelength $(\lambda)$ at $25^{\circ} \mathrm{C}$ in case of Allium dye. a represents plot in absence of surfactant. $b$ and $c$ are in presence of $0.05 \mathrm{~g} / \mathrm{l}$ of NaLS and CTAB, respectively. Allium dye $=1.0 \mathrm{~g} / \mathrm{l}$.

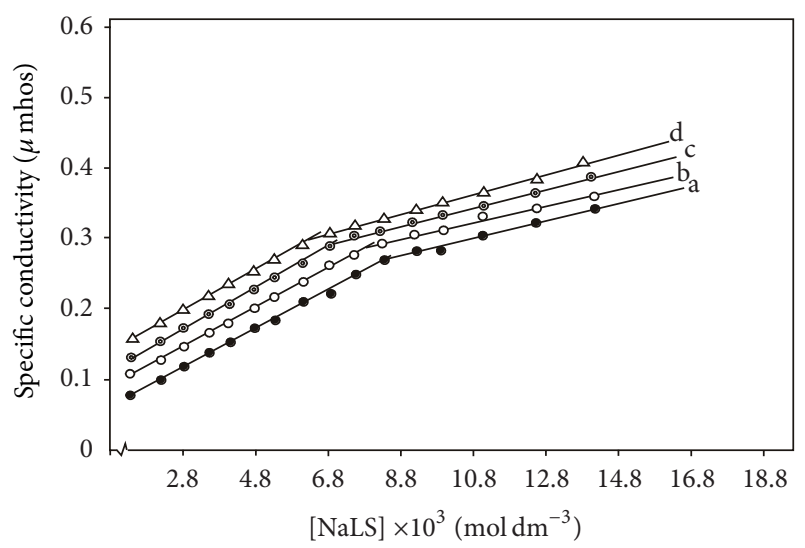

FIGURE 2: Plots of (Specific Conductivity) versus [NaLS] at $25^{\circ} \mathrm{C}$. a, $\mathrm{b}, \mathrm{c}$ are in presence of $\mathrm{Nil}, 0.1,0.2$, and $0.3 \mathrm{~g} / \mathrm{l}$, respectively.

is probably due to an increase in the charged density at the micelle surface.

The standard Gibbs free energy for the micelle formation $\left(\Delta G^{\circ}{ }_{\text {mic }}\right)$ was obtained by using following relation [20]:

$$
\Delta G_{\text {mic }}^{\circ}=2.303 R T(\log \mathrm{CMC}-\log \omega),
$$

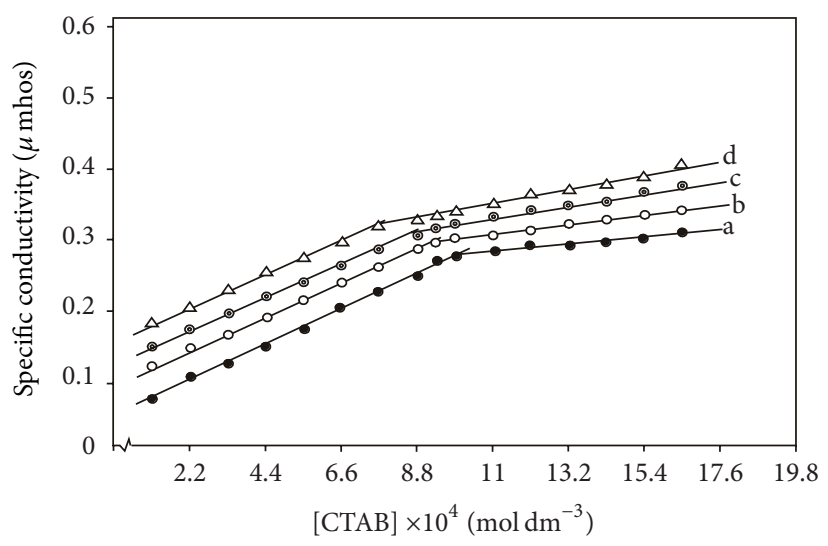

FIGURe 3: Plots of (Specific Conductivity) versus [CTAB] at $25^{\circ} \mathrm{C}$. a, $\mathrm{b}, \mathrm{c}$, and $\mathrm{d}$ are in presence of Nil, $0.1,0.2$, and $0.3 \mathrm{~g} / \mathrm{l}$ dye, respectively.

where " $\omega$ " is the $\left(\Delta S^{\circ}\right.$ mic $)$ and standard entropy change $\left(\Delta H^{\circ}{ }_{\text {mic }}\right)$ for the micelle molar concentration of water, that is, 55.3 at $25^{\circ} \mathrm{C}, R=8.314 \mathrm{~J} \mathrm{~mol}^{-1} \mathrm{~K}^{-1}$ and $T$ is temperature in Kelvin.

Further, the standard entropy change formation was calculated using the following relations [20]:

$$
\begin{gathered}
\Delta S_{\text {mic }}^{\circ}=-\frac{d\left(\Delta G^{\circ} \text { mic }\right)}{d t}, \\
\Delta G^{\circ}{ }_{\text {mic }}=\Delta H^{\circ}{ }_{\text {mic }}-T \Delta S^{\circ}{ }_{\text {mic }} .
\end{gathered}
$$

In Table 2, the values of thermodynamic parameters, namely, $\Delta G^{\circ}{ }_{\text {mic }}, \Delta H^{\circ}{ }_{\text {mic }}$, and $\Delta S^{\circ}{ }_{\text {mic }}$ in both the cases, that is, interaction of dye with NaLS and CTAB are reported. The negativity of values of $\Delta G^{\circ}$ mic in each case favors the micellization. The value of $\Delta G^{\circ}$ mic becomes more negative at higher dye content indicating micellization/aggregation becomes more favorable at higher dye content. The positive entropy change $\left(\Delta S^{\circ}\right.$ mic $)$ upon aggregation is major contribution to the negative values of free energy change $\left(\Delta G^{\circ}\right.$ mic $)$ and thus is the main driving force responsible for the aggregation. The entropy that increases on micellization in aqueous medium has been explained either (i) on the basis of structuring of the water molecules surrounding the hydrocarbon chains in aqueous medium, resulting in an increase in the entropy of 
TABLE 3: Surface parameters for interaction of dyes with surfactants at $25^{\circ} \mathrm{C}$ by surface tension measurement.

\begin{tabular}{|c|c|c|c|c|c|c|c|c|c|}
\hline Surfactant & $\begin{array}{c}{[\text { Dye }]} \\
\text { added } \\
(\mathrm{g} / \mathrm{L})\end{array}$ & $\begin{array}{c}\mathrm{CMC} \\
\left(\mathrm{mol} \mathrm{dm}^{-3}\right)\end{array}$ & $\begin{array}{c}\text { Surface excess } \\
\text { concentration } \\
\Gamma \times 10^{10} \\
\left(\mathrm{~mol} \mathrm{~cm}^{-2}\right)\end{array}$ & $\begin{array}{c}\text { Area per } \\
\text { molecule at } \\
\text { interface } \\
a_{1}^{s} \\
\left(\mathrm{~A}^{\circ}\right)^{2}\end{array}$ & $p C_{20}$ & $\begin{array}{c}-\Delta G_{\mathrm{ad}}^{\circ} \pm 0.05 \\
\left(\mathrm{~kJ} \mathrm{~mol}^{-1}\right)\end{array}$ & $\begin{array}{l}\Delta S_{\mathrm{ad}}^{\circ} \pm 0.10 \\
\left(\mathrm{JK}^{-1} \mathrm{~mol}^{-1}\right)\end{array}$ & $\begin{array}{c}\Delta H_{\mathrm{ad}}^{\circ} \pm 0.05 \\
\quad\left(\mathrm{~J} \mathrm{~mol}^{-1}\right)\end{array}$ & $\mathrm{CMC} / C_{20}$ \\
\hline \multirow{4}{*}{$\begin{array}{l}\text { CTAB } \\
(0.02 \mathrm{~g} / \mathrm{L})\end{array}$} & Nil & $9.6 \times 10^{-4}$ & 2.19 & 75.8 & 3.07 & 36.59 & 122.78 & +1.07 & 1.12 \\
\hline & 0.1 & $9.1 \times 10^{-4}$ & 1.97 & 84.3 & 3.17 & 38.18 & 128.12 & -2.10 & 1.34 \\
\hline & 0.2 & $8.6 \times 10^{-4}$ & 1.75 & 94.3 & 3.35 & 40.49 & 135.85 & -2.49 & 1.92 \\
\hline & 0.3 & $7.5 \times 10^{-4}$ & 1.53 & 108.5 & 3.57 & 43.37 & 145.50 & -2.91 & 2.78 \\
\hline \multirow{4}{*}{$\begin{array}{l}\mathrm{NaLS} \\
(0.20 \mathrm{~g} / \mathrm{L})\end{array}$} & $\mathrm{Nil}$ & $8.1 \times 10^{-3}$ & 1.97 & 84.3 & 2.17 & 32.47 & 108.97 & -2.96 & 1.19 \\
\hline & 0.1 & $7.5 \times 10^{-3}$ & 1.75 & 94.9 & 2.35 & 34.78 & 116.70 & -3.35 & 1.68 \\
\hline & 0.2 & $6.5 \times 10^{-3}$ & 1.53 & 108.5 & 2.49 & 37.22 & 124.80 & -3.85 & 2.01 \\
\hline & 0.3 & $6.0 \times 10^{-3}$ & 1.31 & 126.7 & 2.60 & 40.02 & 134.30 & -4.22 & 2.39 \\
\hline
\end{tabular}

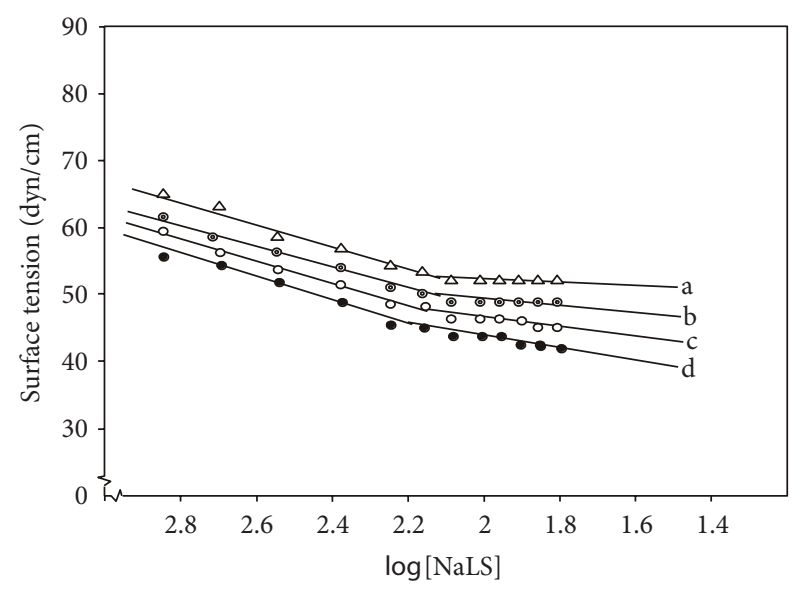

FIGURE 4: Plots of (Surface Tension) versus log [NaLS] at $25^{\circ} \mathrm{C} . \mathrm{a}, \mathrm{b}$, $\mathrm{c}$ and $\mathrm{d}$ are same as in Figure 2.

the system when the hydrocarbon chains are removed from the aqueous medium to the interior of micelle or (ii) on the basis of increased freedom of the hydrophobic chain in the nonpolar interior of the micelle compared to the aqueous environment.

The water molecules around the hydrocarbon chain form a solvation layer, during the dissolution of surfactant in water. Thus, due to formation of solvation layer with highly ordered water molecules, the entropy of the system increases making the dissolution of the hydrocarbon chains highly unfavorable. The aggregation of surfactant into micelles within which the hydrocarbon chains are located in the interior and the molecules are anchored at the interface by hydrophilic head groups (remaining in contact with water), however, decreases the extent of solvation layer. Thus, the aggregation releases the mobility constraint on water molecules and therefore results in a favorable increase in the entropy.

The values of $\Delta G^{\circ}$ mic and $\Delta S^{\circ}$ mic also indicate the micellization of the dye with cationic surfactant; that is, CTAB is more favorable as compared to NaLS.

2.3. Surface Tension and Surface Parameters. The surface tension of surfactant and mixtures of the surfactant and dye were

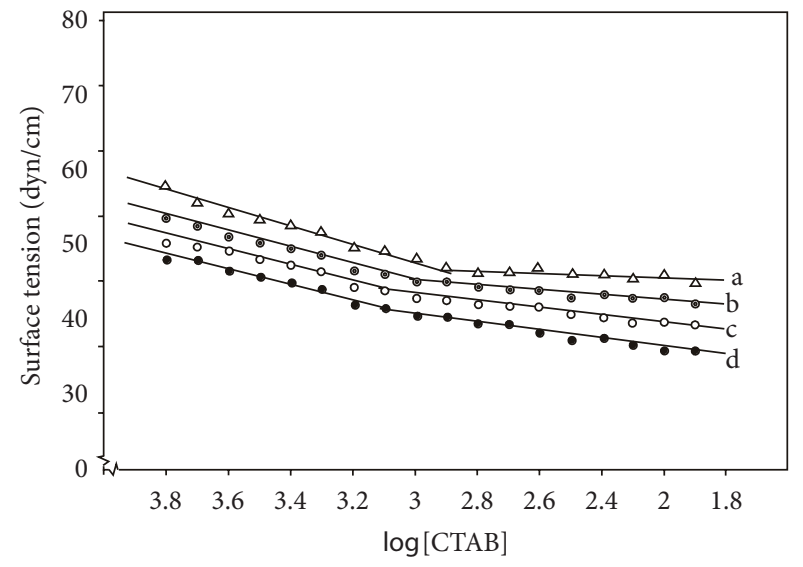

Figure 5: Plots of (Surface Tension) versus $\log [\mathrm{CTAB}]$ at $25^{\circ} \mathrm{C}$. a, $\mathrm{b}, \mathrm{c}$, and $\mathrm{d}$ are the same as in Figure 3.

determined at $25^{\circ} \mathrm{C}$. The surface tension of NaLS and CTAB in absence and presence of varying added amount of dye is represented as (Surface Tension) versus log [Surfactant], Figures 4 and 5 in case of NaLS and CTAB, respectively. The values of CMC at different additive dye obtained from break point of (Surface Tension) versus log [surfactant] are given in Table 3. A decrease in CMC on increasing the dye concentration has been observed in both the cases. The reduction in surface tension on addition of dye indicates the formation of \{dye-surfactant complex due to binding of surfactant with dye.

The concentration of the surfactant at the interface may be calculated from surface or interfacial data by the use of Gibbs equation [20]:

$$
\tau_{1}\left(\mathrm{~mol} \mathrm{~cm}^{-1}\right)=-\frac{1}{2.303 R T}\left[\frac{\partial \gamma}{\partial \log C}\right],
$$

where $\gamma$ is the surface tension in $\mathrm{dyn}^{-1}$ or ergs $\mathrm{cm}^{-2} R=$ $8.31 \times 10^{7} \mathrm{ergs} \mathrm{mol}^{-1} \mathrm{~K}^{-1}$ and $C$ is the concentration of surfactant.

The value of surface excess concentration $\left(\Gamma_{1}\right)$ in each case has been calculated and reported in Table 3. It has been 
observed from the value that $\Gamma_{1}$ decreases on increasing the dye content in the mixture.

From the surface excess concentration, the area per molecule at the surface/interface $\left(a_{1}^{s}\right)$ in square angstroms has been calculated using following relation [20]:

$$
a_{1}^{s}=\frac{10^{16}}{N \Gamma_{1}}
$$

where $N$ is Avogadro's number.

The area per molecule at the interface $\left(a_{1}^{s}\right)$, which provides information of the degree of packing, is found to increase on increasing dye content in the mixture (Table 3 ).

The another parameter, which measures the concentration of surfactant in the liquid phase required to produce at given amount of adsorption at the interface, is the negative logarithm of the concentration of surfactant in the bulk phase required to produce a $20 \mathrm{dyn} / \mathrm{cm}$ reduction in the surface tension of the solvent, that is, $-\log C(-\Delta \gamma=20)$ called $p C_{20}$. The larger the value of $p C_{20}$, the more efficiently it reduces surface or interfacial tension. The values of $p C_{20}$ at different added dye contents in the mixture are given in Table 3 . The value of $p C_{20}$ was found to increase on increasing the amount of dye in the mixture.

The thermodynamic parameters of adsorption, that is, Gibbs free energy $\left(\Delta G^{\circ}\right.$ ad $)$, standard enthalpy change $\left(\Delta H^{\circ}{ }_{\text {ad }}\right)$, and standard entropy change $\left(\Delta S^{\circ}{ }_{\text {ad }}\right)$ have also been calculated by using the following relation [20]:

$$
\begin{aligned}
& \Delta G^{\circ}{ }_{\text {ad }}=-(2.303 R T) \times p C_{20}-6.023 \\
& \times 20 \times a_{1}^{s}-2.303 R T \log \omega, \\
& \Delta S_{\mathrm{ad}}^{\circ}=\frac{d\left(\Delta G_{\mathrm{ad}}^{\circ}\right)}{d t}, \\
& \Delta G^{\circ}{ }_{\text {ad }}=\Delta H^{\circ}{ }_{\text {d }}-T \Delta S_{\text {ad }}^{\circ} \text {, }
\end{aligned}
$$

where $\omega, R$, and $T$ are the same as defined in (1).

As the values of $\Delta G^{\circ}$ ad are negative indicating that the adsorption is spontaneous process, it is also observed that the adsorption becomes more favorable at high dye content. The negative values of $\Delta G_{\mathrm{ad}}^{\circ}$ are mainly due to the large positive values of $\Delta S^{\circ}$ ad and entropy change is a driving force as discussed in micellization.

A convenient way of measuring the relative effects of some structural factor on micellization and or adsorption is to determine its effect on $\mathrm{CMC} / \mathrm{C}_{20}$ ratio (where $C_{20}$ is the concentration of the surfactant in bulk phase required to produce a $20 \mathrm{dyn}^{-1}$ reduction in the surface tension of the solvent).

An increase in the $\mathrm{CMC} / \mathrm{C}_{20}$ ratio as a result of the introduction of some factor indicates that the adsorption is facilitated more than micellization [20]. The values of $\mathrm{CMC} / \mathrm{C}_{20}$ are reported in Table 3. Increase in $\mathrm{CMC} / \mathrm{C}_{20}$ value on addition of dye content indicates the facilitation of adsorption.

\section{Conclusion}

The results indicate the formation of \{surfactant-dye $\}$ aggregation and more facilitation of adsorption in comparison to micellization.

\section{Acknowledgment}

The authors thank All India Council of Technical Education, New Delhi (India), for financial support through a major research project.

\section{References}

[1] A. K. Samanta and P. Agarwal, "Application of natural dyes on textiles," Indian Journal of Fibre \& Textile Research, vol. 34, no. 4, pp. 384-399, 2009.

[2] M. L. Gulrajani and G. Deepti, Natural Dyes and Their Applications to Textiles, Department of Textile Technology, Indian Institute of Technology, Delhi, Indian, 1992.

[3] P. S. Vankar, V. Tiwari, and B. Ghorpade, Natural Dyes: Convention Proceedings, Indian Institute of Technology, Delhi, Indian, 2001, edited by D. Gupta and M. L. Gulrajani.

[4] P. S. Vankar, "Chemistry of natural dyes," Resonance, vol. 5, pp. 73-80, 2000.

[5] T. Bechtold, A. Turcanu, E. Ganglberger, and S. Geissler, "Natural dyes in modern textile dyehouses," Journal of Cleaner Production, vol. 11, no. 5, pp. 499-509, 2003.

[6] S. Adeel, S. Ali, L. A. Bhatti, and F. Zsila, "Dyeing of cotton fabric using pomegranate (Punica granatum) aqueous extract," Asian Journal of Chemistry, vol. 21, no. 5, pp. 3493-3499, 2009.

[7] S. Naz, I. A. Bhattia, and S. Adeel, "Dyeing properties of cotton fabric using un-irradiated and gamma irradiated extracts of Eucalyptus camaldulensis bark powder," Indian Journal of Fibre \& Textile Research, vol. 36, no. 2, pp. 132-136, 2011.

[8] S. Gokturk and M. Tuncay, "Dye-surfactant interaction in the premicellar region," Journal of Surfactants and Detergents, vol. 6, no. 4, pp. 325-330, 2003.

[9] M. Ali Awan and S. S. Shah, "Hydrophobic interaction of amphiphilic hemicyanine dyes with cationic and anionic surfactant micelles," Colloids and Surfaces A, vol. 122, no. 1-3, pp. 97-101, 1997.

[10] M. Sarkar and S. Poddar, "Spectral studies of methyl violet in aqueous solutions of different surfactants in supermicellar concentration region," Spectrochimica Acta-Part A, vol. 55, no. 9, pp. 1737-1742, 1999.

[11] M. G. Neumann and M. H. Gehlen, "The interaction of cationic dyes with anionic surfactants in the premicellar region," Journal of Colloid And Interface Science, vol. 135, no. 1, pp. 209-217, 1990.

[12] M. Abe, M. Ohsato, and K. Ogino, "Interaction between anionic surfactants and oil dye in the aqueous solutions," Colloid \& Polymer Science, vol. 262, no. 8, pp. 657-661, 1984.

[13] L. García-Río, P. Hervella, J. C. Mejuto, and M. Parajó, "Spectroscopic and kinetic investigation of the interaction between crystal violet and sodium dodecylsulfate," Chemical Physics, vol. 335, no. 2-3, pp. 164-176, 2007.

[14] B. Simončič and M. Kert, "A study of anionic dye-cationic surfactant interactions in mixtures of cationic and nonionic surfactants," Dyes and Pigments, vol. 54, no. 3, pp. 221-237, 2002. 
[15] S. Acharya and B. Rebery, "Fluorescence spectrometric study of eosin yellow dye-surfactant interactions," Arabian Journal of Chemistry, vol. 2, no. 1, pp. 7-12, 2009.

[16] S. Chandravanshi and S. K. Upadhyay, "Natural dye-surfactant Interaction: thermodynamic and surface parameters," Coloration Technology, vol. 128, no. 4, pp. 300-305, 2011.

[17] A. Önal, "Extraction of dyestuff from onion (Allium cepa L.) and its application in the dyeing of wool, feathered-leather and cotton," Turkish Journal of Chemistry, vol. 20, no. 3, pp. 194-203, 1996.

[18] T. F. Tadros, Surfactants in Agrochemicals, vol. 54, Marcel Dekker, New York, NY, USA, 1995.

[19] K. Holmberg, B. Johnson, B. Kronberg, and B. Lindman, Surfactants and Polymers in Aqueous Solutions, John Wiley \& Sons, New York, NY, USA, 1997.

[20] M. J. Rosen, Surfactants and Interfacial Phenomena, John Wiley \& Sons, Hoboken, NJ, USA, 3rd edition, 2004. 

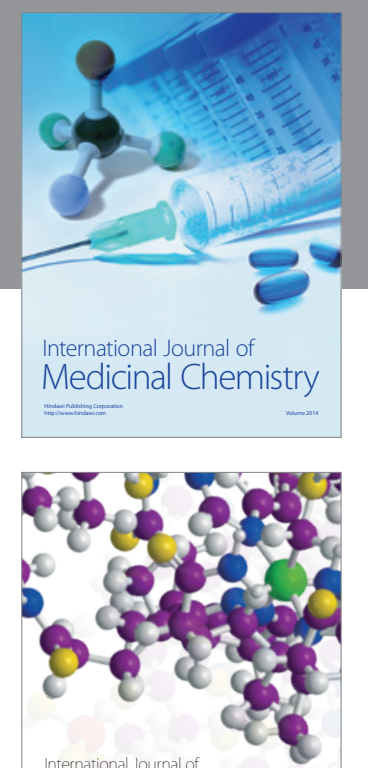

\section{Carbohydrate} Chemistry

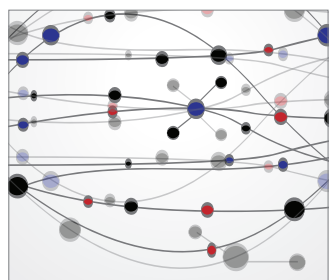

The Scientific World Journal
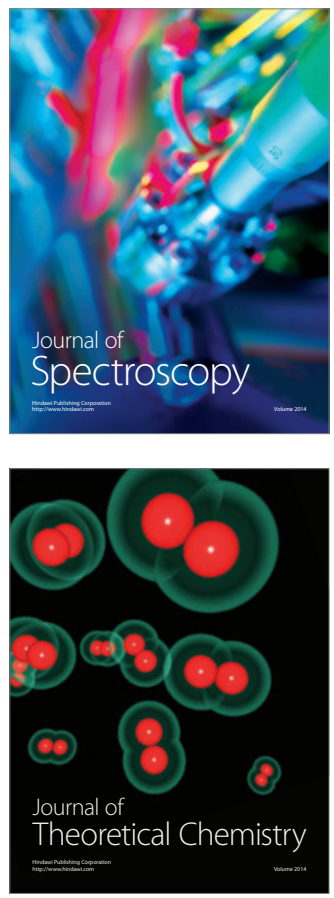
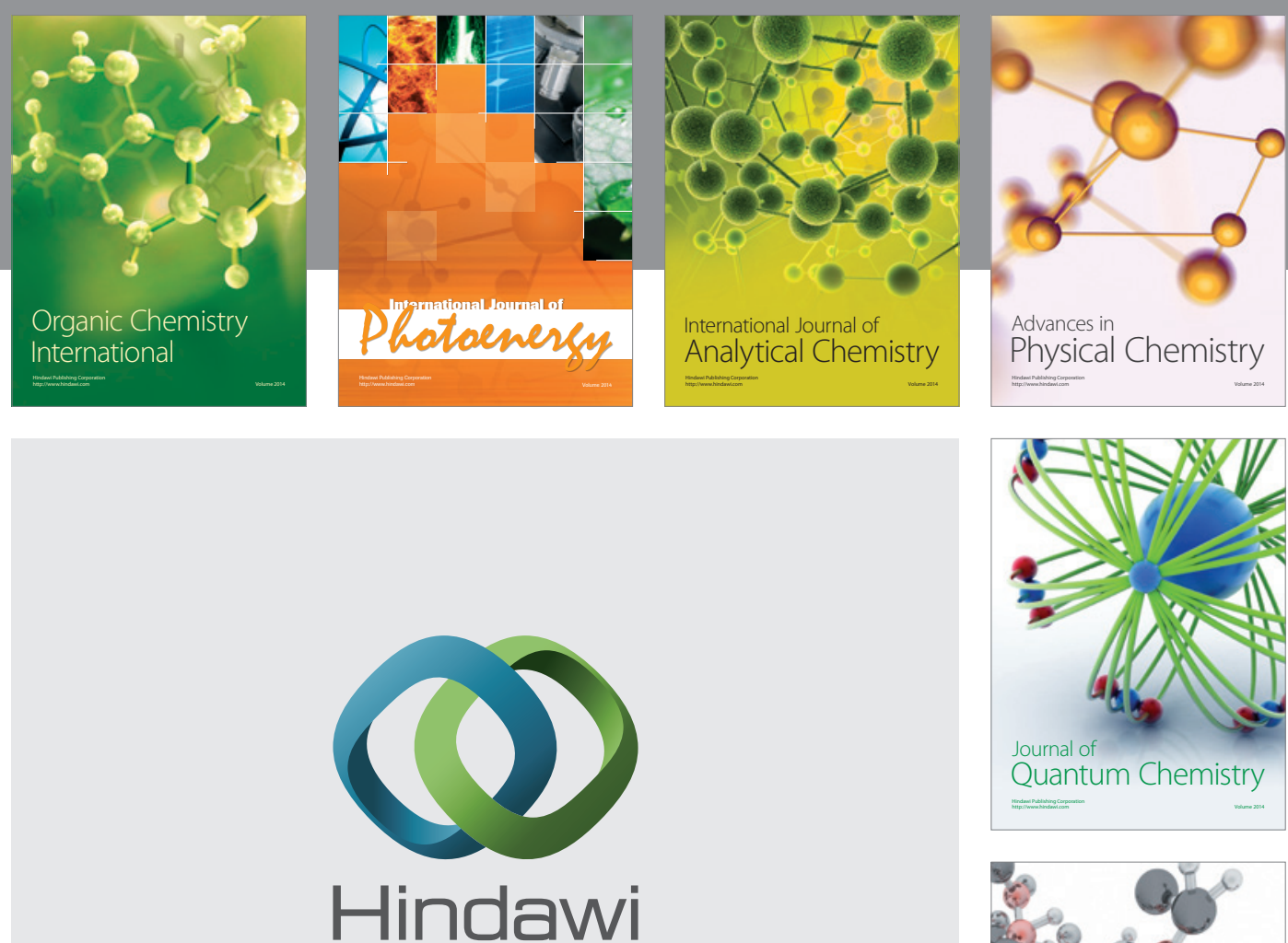

Submit your manuscripts at

http://www.hindawi.com

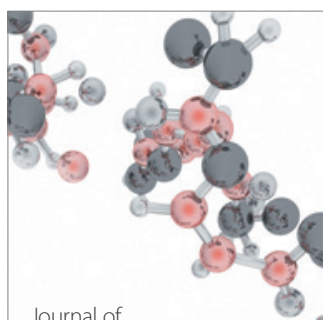

Analytical Methods

in Chemistry

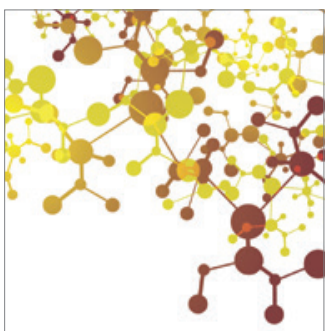

Journal of

Applied Chemistry

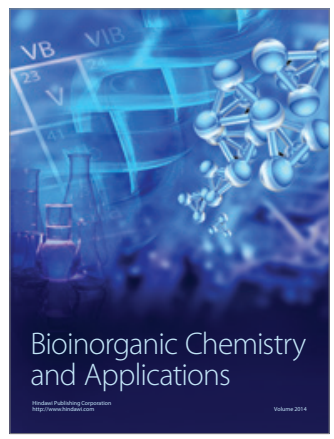

Inorganic Chemistry
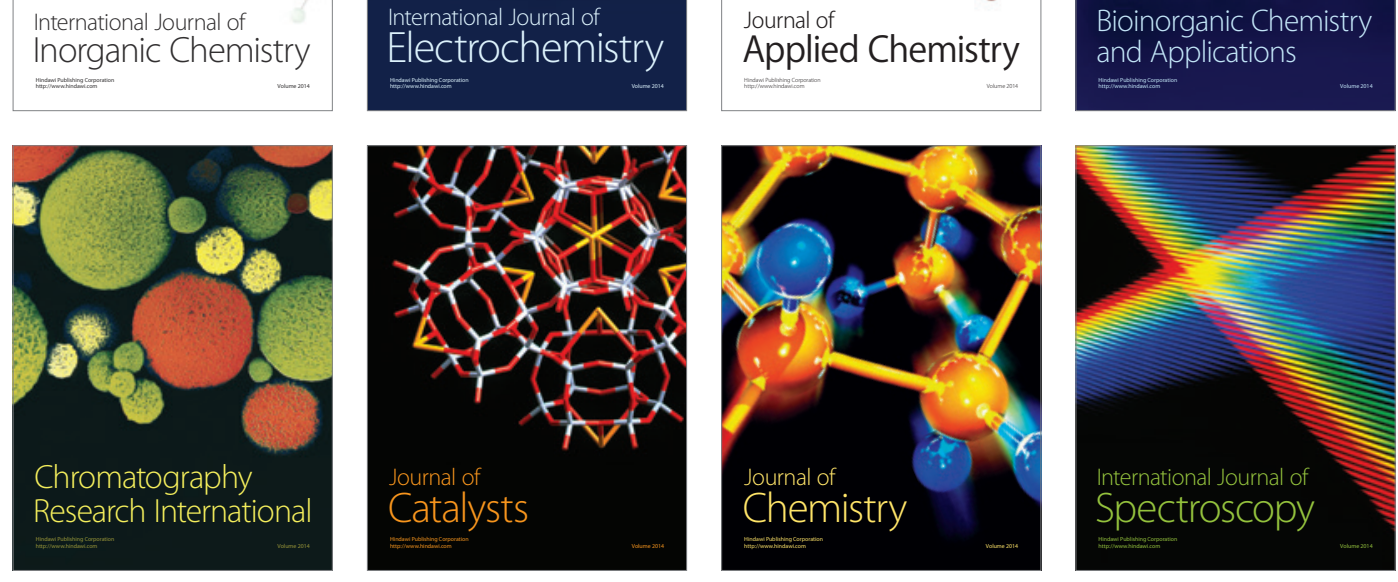